\title{
Comparing self-reported medication adherence measures with hair antiretroviral concentration among people living with HIV in Guangxi, China
}

\author{
Quan Zhang ${ }^{1,2^{*}}$, Xiaoming $\mathrm{Li}^{1}$, Shan Qiao ${ }^{1}$, Zhiyong Shen ${ }^{3}$ and Yuejiao Zhou ${ }^{3}$
}

\begin{abstract}
Background: Antiretroviral adherence is essential to HIV treatment efficacy. Various self-reported measures are commonly used for assessing antiretroviral adherence. Limited data are available regarding the validity of those selfreported measures in comparison with long-term objective biomarkers of adherence measures such as hair measures.

Methods: Self-reported adherence (frequency, percentage, and visual analog scale [VAS]) and hair tenofovir concentration were evaluated at a single time point from 268 people living with HIV in China. The responses to each of three self-reported measures were converted into percentage and then dichotomized as "optimal" (100\%) vs. "suboptimal" (less than 100\%) adherence. Two composite adherence scores (CAS) were created from the three self-reported measures: (1) an overall adherence was the average percentage of the three self-reported measures; (2) responses were termed optimal adherence if participants reporting optimal adherence in all three self-reported measures, while were termed suboptimal adherence. Hair tenofovir concentration was also dichotomized as "optimal" (above the limit of quantitation, $36 \mathrm{pg} / \mathrm{mg}$ ) vs. "suboptimal" adherence (blow 36 pg/mg). Spearman correlation, kappa statistics, and logistic regression analysis were used to calculate the correlations, agreements, and predictions of self-reported measures with hair measure, respectively.
\end{abstract}

Results: Overall adherence, but any of the three self-reported adherence, was correlated with hair tenofovir concentration $(r=0.13, p<0.05)$. Self-reported optimal adherence in VAS and CAS measures were agreed with and predicted optimal adherence assessed by hair measure (Kappa $=0.107$, adjusted $O R=1.88,95 \% \mathrm{Cl} 1.03-3.45$; Kappa $=0.109$, adjusted $\mathrm{OR}=1.80,95 \% \mathrm{Cl} 1.02-3.18$; all $p<0.05$, respectively).

Conclusion: VAS may be a good individual self-reported measure for antiretroviral adherence, and CAS may be a good composite self-reported measure for antiretroviral adherence.

Keywords: Antiretroviral adherence, Self-report, Hair concentration, Tenofovir, People living with HIV

*Correspondence: quanz@mailbox.sc.edu; zhangquan02@hhu.edu.cn 1 South Carolina SmartState Center for Healthcare Quality (CHQ), Arnold School of Public Health, University of South Carolina, Discovery I, 915 Greene Street, Columbia, SC 29028, USA

Full list of author information is available at the end of the article

\section{Background}

In China, antiretroviral therapy (ART) has been available for HIV treatment at no cost to people living with HIV (PLHIV) for more than a decade. However, despite the increased availability of antiretroviral medications, HIV-related morbidity, mortality, and new infection rate continually increased over the years in China from 2004 to 2016 [1]. Both clinical trials and cohort studies have

c) The Author(s) 2020. This article is licensed under a Creative Commons Attribution 4.0 International License, which permits use, sharing, adaptation, distribution and reproduction in any medium or format, as long as you give appropriate credit to the original author(s) and the source, provide a link to the Creative Commons licence, and indicate if changes were made. The images or other third party material in this article are included in the article's Creative Commons licence, unless indicated otherwise in a credit line to the material. If material is not included in the article's Creative Commons licence and your intended use is not permitted by statutory regulation or exceeds the permitted use, you will need to obtain permission directly from the copyright holder. To view a copy of this licence, visit http://creativeco mmons.org/licenses/by/4.0/. The Creative Commons Public Domain Dedication waiver (http://creativecommons.org/publicdomain/ zero/1.0/) applies to the data made available in this article, unless otherwise stated in a credit line to the data. 
shown that the effectiveness of antiretroviral medications is highly dependent on adherence [2-4]. Suboptimal adherence severely undercuts antiretroviral effectiveness and places PLHIV at risk for virologic failure, increases the risk of onward HIV transmission, and limits the impact of HIV treatment resources [5, 6]. Detecting and addressing suboptimal adherence to antiretroviral is an essential component of HIV treatment and management in China and other countries. Consequently, one of the challenges is how to assess antiretroviral adherence accurately.

Currently, antiretroviral adherence measures vary widely, and there is still no single "gold standard" for accurate measurement of adherence [7, 8]. With the desires for objective and accurate measures, researchers employed medication electronic drug monitoring [9], pharmacodynamics responses (e.g., viral load) [10], or antiretroviral concentration in various pharmacokinetic metrics such as plasma [11], saliva [12], urine [13], dried blood spots [14], and hair [15]. However, these measures are often impractical in resource-limited settings because of the high cost and logistic complexities $[7,8,16]$. Alternatively, researchers have employed various self-reported measures that differ in content (e.g., pill taken or pill missed), response option (e.g., percentage or rating), and recall timeframe (e.g., 3 days or 30 days) to estimate adherence [17-20]. Self-report remains the most widely and frequently used method in measuring antiretroviral adherence because of its low-cost, noninvasiveness, minimal patient burden, and ease of administration [17, 21]. However, because of possible biases inherent in selfreporting (e.g., social desirability, memory decay, inaccuracy in estimation, and error of recall) [22, 23], examining the validity of various self-reported measures has been a focus of recent research.

Several studies have examined the concurrent validity of various self-reported measures with other devicebased measures [17] or biological measures (e.g., viral load, and antiretroviral concentration in various pharmacokinetic metrics) [10, 19, 24-26]. While these studies provide important information regarding the validity of self-reported measures, data are limited in Chinese PLHIV and comparison of those self-reported measures with long-term biological measures of adherence. In addition, some studies used a composite adherence score (CAS) from several self-reported measures with the hope to offset or reduce potential biases in self-reporting [27-29]. Several studies employed CAS measures to predict objective measures of adherence (e.g., device-based measures and viral load) $[17,18,26]$, and did not find advantages over the individual self-reported measures. However, it is unclear whether CAS will offer advantages over the individual self-reported measures in predicting biological measures of adherence that reflects long-term antiretroviral exposure.

Given antiretroviral concentration in hair reflects uptake from the systemic circulation over an extended time window and human hair grows at an average rate of $1 \mathrm{~cm}$ per month, antiretroviral concentration in $1 \mathrm{~cm}$ hair approximately represents a 1-month window of antiretroviral exposure. Therefore, Hair antiretroviral concentration has been considered as a long-term adherence biomarker [30,31]. One of the most commonly used antiretroviral components is tenofovir disoproxil fumarate (TDF) which has been provided at no-cost to PLHIV in China by the Chinese government since 2012. Hair tenofovir concentration has been used as a longterm adherence biomarker among PLHIV [32] and populations at risk for HIV infection [33-35] in the US and Africa. More importantly, Liu et al. directly observed a strong linear relationship between the frequency of TDF dosing and hair tenofovir concentration in healthy volunteers that could provide a valid standard for comparing self-reported measures [36].

Therefore, the present study was designed to compare three common self-reported measures and their CAS with hair tenofovir concentration among PLHIV received TDF-based ART in China. We plan to examine the relationships between self-reported adherence and hair tenofovir concentration at a single study visit.

\section{Methods \\ Study participants}

Data used in the current study were collected from September 2016 to January 2017 as part of an HIV disclosure study among 446 PLHIV in Guangxi, China [37]. With the assistance and collaboration of Guangxi Center for Disease Prevention and Control (Guangxi CDC), we randomly selected 10 sites with the largest number of HIV/ AIDS cases from 17 cities and 75 counties in Guangxi. With the referral from medical staff or HIV case managers at the study sites, local team members screened PLHIV for eligibility and discussed the benefits and risks of the study and invited them to join. After obtaining written informed consent, participants completed the survey one-on-one with an interviewer in private rooms of the clinics. The interviewers were medical staff or HIV case managers in the HIV clinics who had received intensive training on research ethics and interview skills with PLHIV prior to the field data and hair specimen collection.

\section{Hair collection and assay}

Approximately 150 strands of hair were cut from the posterior vertex region as close as possible to the scalp following a standard protocol $[38,39]$ after participants 
finished the survey. The proximal section of the hair sample (about $1 \mathrm{~cm}$, reflecting the last month of TDF dosing) was rinsed with methanol and dried under a blow of pure nitrogen gas. Then hair sample was chopped to 1-2 mm length segments with scissors, and $10 \mathrm{mg}$ weighed, processed, and analyzed using highperformance liquid chromatography (Agilent 1200 HPLC system, Agilent, Waldbronn, Germany) and tandem mass spectrometry (ABI 3200Qtrap, ABI, Foster City, CA, USA) (LC-MS/MS) [40, 41]. Briefly, following the 2013 FDA guideline, The tenofovir in the cut hair sample was extracted with methanol and internal standard in a $37^{\circ} \mathrm{C}$ shaking water bath overnight $(>16 \mathrm{~h})$ and then analyzed by an LC-MS/MS [40]. Standard curves were linear in the range of 36-1250 mg with good linearity $\left(R^{2}=0.994\right)$ and reproducibility. The relative error (\%) and precision [coefficients of variation $(\mathrm{CV})$ ] for spiked quality control hair samples at low, medium and high concentrations were all $<12 \%$. The recoveries at low, medium and high concentrations were all $\geq 98.2 \%$. The limit of quantitation (LOQ) was $36 \mathrm{pg} / \mathrm{mg}$. No significant matrix ionization suppression was observed.

Based on two previous studies, adherence was defined as detectable antiretroviral in dried blood spots [24], and the range of hair tenofovir concentration was 21 to $53 \mathrm{pg} / \mathrm{mg}$ when the subject took TDF 7 days/week (100\% adherence) [36], we defined hair measure of optimal adherence as hair tenofovir concentration above LOQ, and suboptimal adherence as hair tenofovir concentration below LOQ.

\section{Self-reported measures}

\section{Frequency of adherence behavior}

The participants were asked the overall frequency of their adherence behavior via the question: "In last month, how often did you take all your HIV medications as your doctor prescribed them?" with a 5-point response option (none of the time, few of the time, some of the time, most of the time, all of the time) [17]. The responses to frequency measure were quantified in $25 \%$ increments (e.g., none of the time $=0 \%$, few of the time $=25 \%$, some of the time $=50 \%$, most of the time $=75 \%$, and all of the time $=100 \%)[19]$.

\section{Percent of days of adherence}

The participants were asked the question: "In last month, how many days were you able to take your medications exactly as prescribed?". The percent of days of adherence was calculated by dividing the reported number of days by 30 days and then converted into a percentage [10].

\section{Visual analog scale}

A modified visual analog scale (VAS) [21] for missing doses was employed with the following instruction: "Place a mark $(\mathrm{X})$ at the point on the line that shows your best guess about how many of you prescribed medications you have missed in last month." The 11 possible responses to the scale ranged from " 0 " representing no missing doses, " 5 " representing missing half doses, to "10" representing missing all doses. The responses to VAS were appropriately converted into percent of adherence in $10 \%$ increments (e.g., "0" was assigned $100 \%$, and " 10 " was assigned $0 \%$ ) with a higher percentage indicating a better adherence behavior [17].

\section{Composite adherence scores}

Given that self-reported data are generally skewed and overestimated, the responses to each of three selfreported measures were converted into percentage and then dichotomized as "optimal" (100\%) vs. "suboptimal" (less than 100\%) adherence. Two CAS were created from the three self-reported measures: (1) an overall adherence was the average percentage of the three selfreported measures; (2) responses were termed optimal adherence if participants reporting optimal adherence in all three self-reported measures, while were termed suboptimal adherence.

\section{Covariates}

Participants provided information on their socio-demographic and HIV-related characteristics including age, sex, ethnicity, marital status, work status, education experience, monthly household income, ART regimen, duration of HIV diagnosis, and duration of TDF-based ART. The duration of HIV diagnosis and TDF-based ART referred to the time period from the initial date of confirmed HIV diagnosis and the start date of TDF-based ART to the date of survey, respectively.

\section{Statistical analysis}

The self-reported adherence was treated as both continuous and dichotomous (Optimal vs. suboptimal adherence) in the analysis. Likewise, hair tenofovir concentration was also treated as both continuous and dichotomous (Optimal vs. suboptimal adherence). Descriptive statistics were used to summarize the sample characteristics, self-reported adherence, and hair tenofovir concentration. Spearman correlation was used to calculate the correlations of continuous self-reported measures with continuous hair measure. Kappa statistics were used to calculate the agreements of self-reported measures with hair measure, respectively. Univariate logistic regression analysis was used to calculate the 
predictions of self-reported measures of optimal adherence with hair measure of optimal adherence. Multivariate logistic regression analysis was conducted when the covariates were included in the model. SPSS 26 was used for all statistical analyses.

\section{Results}

Of 10 clinics selected, 293 PLHIV receiving TDF-based ART were identified, of which 25 were excluded because of the insufficient quantity of hair samples for assaying (less than $10 \mathrm{mg}, \mathrm{n}=23$ ) or lack of self-reported measures $(n=2)$, leaving an effective sample of 268 PLHIV with a mean (SD) age of 42 (8) years. Of the participants (Table 1), $69.4 \%$ were men, $70.1 \%$ were of Han ethnicity, $79.5 \%$ were married, $77.2 \%$ were full or part-time employed, and $93.7 \%$ were on TDF-based first-line ART. Less than half (47.8\%) of participants completed no more than elementary education. Most of the sample had low income with $73.9 \%$ reporting a monthly household income of less than 3000 Chinese Yuan (or approximately US\$460 during the time of the survey). The median duration of HIV diagnosis was 17.5 months and the median duration of TDF-based ART was 16.5 months.

As showed in Table 2, the mean percentage of adherence was more than $95 \%$ for all three self-reported and CAS measures. The mean hair tenofovir concentration was $120.75 \mathrm{pg} / \mathrm{mg}$. Spearman correlation statistics showed that only overall adherence, but any of the three self-reported adherence was correlated with hair tenofovir concentration $(r=0.13, p<0.05)$.

As showed in Table 3, the percentages of self-reported optimal adherence were $85.8 \%, 97.4 \%, 76.9 \%, 73.5 \%$ for frequency, percent, VAS, and CAS measure, respectively. The percentage of optimal adherence assessed by hair measure was $46 \%$. Kappa statistics showed that self-reported optimal adherence in VAS and CAS measure, but the other two self-reported measures, agreed with optimal adherence assessed by hair measure $($ Kappa $=0.107, p<0.05$; Kappa $=0.109$; both $p<0.05$, respectively).

Logistic regression analysis showed that self-reported optimal adherence in VAS and CAS measures, but other

Table 1 Characteristics of the study sample

\begin{tabular}{|c|c|c|c|}
\hline Characteristics & All samples & Male & Female \\
\hline n (\%) & $268(100 \%)$ & $185(69.4 \%)$ & $83(30.6 \%)$ \\
\hline Age $(M \pm S D)$, years & $41.9 \pm 7.8$ & $42.1 \pm 7.5$ & $41.6 \pm 8.36$ \\
\hline \multicolumn{4}{|l|}{ Ethnicity, n (\%) } \\
\hline Han & $188(70.1 \%)$ & $135(73.0 \%)$ & $53(63.9 \%)$ \\
\hline Others & $80(29.9)$ & $50(27.0 \%)$ & $30(36.1 \%)$ \\
\hline \multicolumn{4}{|l|}{ Education, n (\%) } \\
\hline Elementary school or below & $128(47.8 \%)$ & $78(42.2 \%)$ & $50(60.2 \%)$ \\
\hline Middle school & $113(44.2 \%)$ & $87(47.0 \%)$ & $26(31.3 \%)$ \\
\hline High school or higher & $27(10.1 \%)$ & $20(10.8 \%)$ & $7(8.4 \%)$ \\
\hline \multicolumn{4}{|l|}{ Marital status, n (\%) } \\
\hline Single & $27(10.1 \%)$ & $26(14.1 \%)$ & $1(1.2 \%)$ \\
\hline Married/cohabitating & $213(79.5 \%)$ & $145(78.4 \%)$ & $67(81.9 \%)$ \\
\hline Others & $28(10.4 \%)$ & $14(7.6 \%)$ & $14(16.9 \%)$ \\
\hline \multicolumn{4}{|l|}{ Work status, n (\%) } \\
\hline Full-time employed & $156(58.2 \%)$ & $121(65.4 \%)$ & $35(42.2 \%)$ \\
\hline Part-time employed & $51(19.0 \%)$ & $24(13.0 \%)$ & $27(32.5 \%)$ \\
\hline Unemployed & $61(22.8 \%)$ & $40(21.6 \%)$ & $21(25.3 \%)$ \\
\hline \multicolumn{4}{|l|}{ Income per month, (yuan), n (\%) } \\
\hline$<1000$ & $51(19.0 \%)$ & $41(22.2 \%)$ & $10(12.0 \%)$ \\
\hline 1000-2999 & 149 (55.6\%) & $96(51.9 \%)$ & $53(63.9 \%)$ \\
\hline$\geq 3000$ & $68(25.4 \%)$ & $48(25.9 \%)$ & $20(24.1 \%)$ \\
\hline \multicolumn{4}{|l|}{ ART regimen } \\
\hline TDF based first-line ART, n (\%) & $251(93.7 \%)$ & $179(96.8 \%)$ & $72(86.7 \%)$ \\
\hline TDF based second-line ART, n (\%) & $17(6.3 \%)$ & $6(3.2 \%)$ & $11(13.3 \%)$ \\
\hline Duration of HIV diagnosis, median (range), months & $17.5(2-37)$ & $17(2-37)$ & $18(3-34)$ \\
\hline Duration of TDF-based ART, median (range), months & $16.5(1-36)$ & $16(1-36)$ & $18(2-34)$ \\
\hline
\end{tabular}

$M$ mean, $S D$ standard deviation, TDF tenofovir disoproxil fumarate, $A R T$ antiretroviral therapy 
Table 2 Correlations among hair and self-report measures

\begin{tabular}{|c|c|c|c|c|c|c|}
\hline Adherence measures & Value, $\mathrm{M} \pm \mathrm{SD}$ (range) & 1 & 2 & 3 & 4 & 5 \\
\hline 1. Frequency, \% & $95.99 \pm 10.83,(25-100)$ & 1 & & & & \\
\hline 2. Percent, $\%$ & $98.18 \pm 10.43,(0-100)$ & $0.39^{* *}$ & 1 & & & \\
\hline 3.VAS, $\%$ & $95.19 \pm 12.56,(0-100)$ & $0.53^{* *}$ & $0.56^{* *}$ & 1 & & \\
\hline 4. Overall adherence, $\%$ & $96.45 \pm 8.45,(27-100)$ & $0.76^{* *}$ & $0.57^{* *}$ & $0.92^{* *}$ & 1 & \\
\hline 5. Hair TFV concentration, pg/mg & $\begin{array}{l}120.75 \pm 290.10 \text {, (below } \\
\text { LOQ-2978.99) }\end{array}$ & 0.06 & 0.05 & 0.12 & $0.13^{*}$ & 1 \\
\hline
\end{tabular}

VAS visual analog scale, TFV tenofovir, $L O D$ limit of quantitation

${ }^{*} p<0.05 ;{ }^{*} p<0.001$

Table 3 Association between hair measure and self-reported measures of optimal adherence

\begin{tabular}{|c|c|c|c|c|c|c|c|c|}
\hline \multirow[t]{2}{*}{ Adherence measures } & & \multicolumn{2}{|c|}{ Hair TFV concentration } & \multirow[t]{2}{*}{ Kappa statistics } & \multicolumn{2}{|c|}{ Univariate model $^{a}$} & \multicolumn{2}{|c|}{ Multivariate model ${ }^{\mathbf{b}}$} \\
\hline & & $\begin{array}{l}\text { Optimal } \\
123(45.9 \%)\end{array}$ & $\begin{array}{l}\text { Suboptimal } \\
145(54.1 \%)\end{array}$ & & cOR $(95 \% \mathrm{Cl})$ & $p$ & aOR $(95 \% \mathrm{Cl})$ & $p$ \\
\hline \multicolumn{9}{|l|}{ Frequency } \\
\hline Optimal & $230(85.8 \%)$ & $109(88.6 \%)$ & $121(83.4 \%)$ & 0.048 & $1.54(0.76,3.14)$ & 0.229 & $1.37(0.66,2.86)$ & 0.400 \\
\hline Suboptimal & $38(14.2 \%)$ & $14(11.4 \%)$ & $24(16.6 \%)$ & & - & - & - & - \\
\hline \multicolumn{9}{|l|}{ Percent } \\
\hline Optimal & $261(97.4 \%)$ & $122(98.4 \%)$ & $140(96.6 \%)$ & 0.017 & $2.16(0.41,11.34)$ & 0.362 & $2.37(0.44,12.95)$ & 0.318 \\
\hline Suboptimal & $7(2.6 \%)$ & $2(1.6 \%)$ & $5(3.4 \%)$ & & - & - & - & - \\
\hline \multicolumn{9}{|l|}{ VAS } \\
\hline Optimal & $206(76.9 \%)$ & $102(82.9 \%)$ & $104(71.7 \%)$ & $0.107^{*}$ & $1.91(1.06,3.46)$ & 0.032 & $1.88(1.03,3.45)$ & 0.041 \\
\hline Suboptimal & $62(23.1 \%)$ & $21(17.1 \%)$ & $41(28.3 \%)$ & & - & - & - & - \\
\hline \multicolumn{9}{|l|}{ CAS } \\
\hline Optimal & $197(73.5 \%)$ & $98(79.7 \%)$ & 99 (68.3\%) & $0.109^{*}$ & $1.82(1.04,3.19)$ & 0.036 & $1.80(1.02,3.18)$ & 0.043 \\
\hline Suboptimal & $71(26.5 \%)$ & $25(20.3 \%)$ & $46(31.7 \%)$ & & - & - & - & - \\
\hline
\end{tabular}

* $<0.05$. Data are in numbers and percentages [n (\%)], TFV is tenofovir. VAS is visual analog scale. CAS is composite adherence score

a Logistic regression; cOR is crude odd ratio; aOR is adjusted odd ratio

b Adjusted for age, sex, ethnicity, marital status, work status, education experience, monthly household income, duration of HIV diagnosis, ART regimen and duration of TDF-based ART

two self-reported measures, predicted optimal adherence assessed by hair measure in both univariate model (crude $\mathrm{OR}=1.91,95 \%$ CI 1.06-3.46; crude OR $=1.82,95 \% \mathrm{CI}$ 1.04-3.19; both $p<0.05$, respectively) and multivariate model (adjusted OR $=1.88,95 \%$ CI 1.03-3.45; adjusted $\mathrm{OR}=1.80,95 \%$ CI 1.02-3.18; both $p<0.05$, respectively).

\section{Discussion}

The present study compared three self-reported measures and their CAS with hair tenofovir concentration among Chinese PLHIV receiving TDF-based therapy. We found that (1) adherence assessed by CAS measure was significantly correlated with hair tenofovir concentration; (2) self-reported optimal adherence in VAS and CAS measures were significantly agreed with optimal adherence assessed by hair measure. (3) Self-reported optimal adherence in VAS and CAS measures were significantly predicted optimal adherence assessed by hair measure.
The finding regarding the weak correlations of adherence assessed by three individual self-reported measures with hair measure was generally in line with previous studies by using tenofovir $[35,42,43]$ and other antiretroviral medications [15, 44-47] in hair, plasma [19] and dried blood spots [24, 26] among PLHIV and populations at risk for HIV infection. The finding regarding the weak agreements of adherence assessed by three individual self-reported measures with hair measure was also generally in line with the previous study by using antiretroviral medications in dried blood spots [26]. The inconsistency between subjective self-reported measures and objective hair measure might be one of the major reasons for the weak associations and agreements. For example, Alcaide et al. data showed that over $80 \%$ of participants reported optimal adherence in 2 individual self-reported measures, but only $74 \%$ of the participants had antiretroviral detected in dried blood spots [24]. Our data showed that 
over $74 \%$ of the participants reported optimal adherence in 3 individual self-reported measures and one CAS measure, but only $46 \%$ of the participants achieved hair measure of optimal adherence.

The finding regarding CAS measures provides an opportunity to improve the accuracy of self-reported measures and the power of these measures in predicting long-term antiretroviral exposure. However, our findings were not totally consistent with previous studies in which composite scores did not show clear advantages over individual measures in terms of their associations with device-based measures and viral load. Lu et al. found that the association of device-based measures with overall adherence from three self-reported measures (rating, frequency, and percent) was similar to that with individual self-reported measures [17]. Kagee and Nel also found that the association between viral load (detectable vs. undetectable) and overall composite adherence score of six self-reported measures was similar to the associations of viral load with individual self-reported measures [18]. The main reason for the inconsistency between our study and the previous studies might be the difference in the criterion measure used in the studies. For example, the device-based measure is relatively objective but it is prone to either underestimation (e.g., device nonuse and pocket dosing) or overestimation (e.g., curiosity opening) of the actual adherence behaviors [8]. Viral load is an objective measure but it is not informative of adherence patterns and the development of viremia usually results long after an adherence gap has occurred [7]. On the other hand, hair antiretroviral concentration is based on drug ingestion in the body system and can provide a more accurate measure of adherence [31], and hair antiretroviral concentration used in this study is a relatively gold standard because the previous study provided the valuable information about the relationship between TDF dosages and hair antiretroviral concentration in healthy volunteers [36].

While our study has strengths in the relatively large sample with adherence assessed by three self-reported measures with a 1-month recall timeframe and antiretroviral concentration in $1-\mathrm{cm}$ hair as a valid biomarker of adherence, there are some limitations. First, the current study was based on cross-sectional data, which prevents making causal inferences. Future research should aim to study the predictive value of self-reported adherence for long-term antiretroviral exposure in longitudinal designs. Second, the current study only employed three single-term self-reported measures. Some other commonly used self-reported measures (e.g., multi-item measure and other types of singleterm measure) need to be validated in the future. Third, the current study employed two different increments to convert the responses of self-reported measures (e.g., 10\% for VAS and 25\% for percent) into percent of adherence. Although these two increments are justified based on the responses to specific measures, the different increments may affect the associations between self-reported measures and hair tenofovir concentration. Fourth, we chose to use hair antiretroviral concentration as a single criterion to test the validity of self-reported measures in this study. While hair antiretroviral concentration has been previously shown to be an excellent measure for long-term antiretroviral exposure [7, 48, 49], future research should employ multiple criteria such as objective device-based measures and biological measures (e.g., hair antiretroviral concentration and viral load) to examine the validity of self-reported measures in HIV research and clinic care. Fifth, data were not available in the current study on some important factors (e.g., substance use) that might influence both self-reported measures and hair antiretroviral concentration $[50,51]$. Those factors should be considered in future research.

\section{Conclusion}

In summary, our findings indicated that CAS may be a good composite self-reported measure for antiretroviral adherence and VAS measure may be a good individual self-reported measure for antiretroviral adherence. Given the importance of adherence in achieving effective HIV treatment, our and previous data also suggest that objective measures of adherence are required in the future due to weak correlations between self-reported measures and objective measures of adherence. However, in the absence of objective measures of adherence, the use of information from multiple self-reported measures for better assessments of antiretroviral medication adherence in HIV research and clinical care in the future, especially in resource-limited settings where the collection and analysis of more objective measures (e.g., hair antiretroviral concentration or other biomarkers) are challenging or unfeasible.

\section{Abbreviations}

CAS: Composite adherence score; HIV: Human immunodeficiency virus; LCMS/MS: Liquid chromatography-tandem mass spectrometry; PLHIV: People living with HIV; TDF: Tenofovir disoproxil fumarate; VAS: Visual analog scale; LOQ: Limit of quantitation.

\section{Acknowledgements \\ The authors wish to thank all participants.}

\section{Authors' contributions}

QZ participated in data analysis, data interpretation, and drafted the manuscript. YJZ and ZYS participated in participant enrollment, and data collection. XML and SQ participated in revised manuscript critically for important intellectual content. All authors read and approved the final manuscript. 


\section{Funding}

This study was funded by the National Institutes of Health $(\mathrm{NIH})$ Research Grant (Grant Numbers R01HD074221, R21Al122919).

\section{Availability of data and materials}

Data will not be shared as the IRB has no policy to share the data without prior permission.

\section{Ethics approval and consent to participate}

This study was approved by ethical review boards of the University of South Carolina, Columbia (USA) and the Guangxi Center for Disease Prevention and Control (Nanning, China). All participants provided written informed consent.

\section{Consent for publication}

Not applicable.

\section{Competing interests}

The authors declare that they have no competing interests.

\begin{abstract}
Author details
${ }^{1}$ South Carolina SmartState Center for Healthcare Quality (CHQ), Arnold School of Public Health, University of South Carolina, Discovery I, 915 Greene Street, Columbia, SC 29028, USA. ${ }^{2}$ Institute of Pedagogy and Applied Psychology, School of Public Administration, Hohai University, Nanjing, Jiangsu, China. ${ }^{3}$ Guangxi Zhuang Autonomous Region Center for Disease Control and Prevention, Nanning, Guangxi, China.
\end{abstract}

Received: 12 November 2019 Accepted: 21 February 2020 Published online: 02 March 2020

\section{References}

1. Qiao YC, Xu Y, Jiang DX, Wang X, Wang F, Yang J, et al. Epidemiological analyses of regional and age differences of HIV/AIDS prevalence in China, 2004-2016. Int J Infect Dis. 2019;81:215-20.

2. Viswanathan S, Justice AC, Alexander GC, Brown TT, Gandhi NR, McNicholl IR, et al. Adherence and HIV RNA suppression in the current era of highly active antiretroviral therapy. J Acquir Immune Defic Syndr. 2015;69(4):493-8.

3. Byrd KK, Hou JG, Hazen R, Kirkham H, Suzuki S, Clay PG, et al. Antiretroviral adherence level necessary for HIV viral suppression using real-world data. J Acquir Immune Defic Syndr. 2019;82(3):245-51.

4. Altice F, Evuarherhe O, Shina S, Carter G, Beaubrun AC. Adherence to HIV treatment regimens: systematic literature review and meta-analysis. Patient Prefer Adherence. 2019;13:475-90.

5. Turner BJ. Adherence to antiretroviral therapy by human immunodeficiency virus-infected patients. J Infect Dis. 2002;185(Suppl 2):S143-51.

6. Chesney M. Adherence to HAART regimens. AIDS Patient Care STDS. 2003;17(4):169-77.

7. Castillo-Mancilla JR, Haberer JE. Adherence measurements in HIV: new advancements in pharmacologic methods and real-time monitoring. Curr HIV/AIDS Rep. 2018;15(1):49-59.

8. Garrison LE, Haberer JE. Technological methods to measure adherence to antiretroviral therapy and preexposure prophylaxis. Curr Opin HIV AIDS. 2017;12(5):467-74.

9. Bangsberg DR, Hecht FM, Charlebois ED, Chesney M, Moss A. Comparing objective measures of adherence to HIV antiretroviral therapy: electronic medication monitors and unannounced pill counts. AIDS Behav. 2001;5(3):275-81.

10. Da W, Li X, Qiao S, Zhou Y, Shen Z. Evaluation of self-report adherence measures and their associations with detectable viral load among people living with HIV (PLHIV) in China. PLoS ONE. 2018;13(8):e0203032.

11. Duong M, Piroth L, Peytavin G, Forte F, Kohli E, Grappin M, et al. Value of patient self-report and plasma human immunodeficiency virus protease inhibitor level as markers of adherence to antiretroviral therapy: relationship to virologic response. Clin Infect Dis. 2001;33(3):386-92.

12. Courlet P, Decosterd LA, Brown JA, Alves Saldanha S, Marzolini C, Cavassini $M$, et al. Emtricitabine and lamivudine concentrations in saliva: a simple suitable test for treatment adherence. J Antimicrob Chemother. 2019;74:2468-70.
13. Gandhi M, Bacchetti P, Rodrigues WC, Spinelli M, Koss CA, Drain PK, et al. Development and validation of an immunoassay for tenofovir in urine as a real-time metric of antiretroviral adherence. EClinicalMedicine. 2018;2-3:22-8.

14. Castillo-Mancilla JR, Searls K, Caraway P, Zheng JH, Gardner EM, Predhomme J, et al. Short communication: Tenofovir diphosphate in dried blood spots as an objective measure of adherence in HIV-infected women. AIDS Res Hum Retroviruses. 2015;31(4):428-32.

15. Hickey MD, Salmen CR, Tessler RA, Omollo D, Bacchetti P, Magerenge $R$, et al. Antiretroviral concentrations in small hair samples as a feasible marker of adherence in rural Kenya. J Acquir Immune Defic Syndr. 2014;66(3):311-5.

16. Brooks KM, Anderson PL. Pharmacologic-based methods of adherence assessment in HIV prevention. Clin Pharmacol Ther. 2018;104(6):1056-9.

17. Lu M, Safren SA, Skolnik PR, Rogers WH, Coady W, Hardy H, et al. Optimal recall period and response task for self-reported HIV medication adherence. AIDS Behav. 2008;12(1):86-94

18. Kagee A, Nel A. Assessing the association between self-report items for HIV pill adherence and biological measures. AIDS Care. 2012;24(11):1448-52.

19. Musinguzi N, Muganzi CD, Boum Y 2nd, Ronald A, Marzinke MA, Hendrix $\mathrm{CW}$, et al. Comparison of subjective and objective adherence measures for preexposure prophylaxis against HIV infection among serodiscordant couples in East Africa. AIDS. 2016;30(7):1121-9.

20. Stirratt MJ, Dunbar-Jacob J, Crane HM, Simoni JM, Czajkowski S, Hilliard $\mathrm{ME}$, et al. Self-report measures of medication adherence behavior: recommendations on optimal use. Transl Behav Med. 2015:5(4):470-82.

21. Simoni JM, Kurth AE, Pearson CR, Pantalone DW, Merrill JO, Frick PA. Self-report measures of antiretroviral therapy adherence: a review with recommendations for HIV research and clinical management. AIDS Behav. 2006:10(3):227-45.

22. Wagner G, Miller LG. Is the influence of social desirability on patients' self-reported adherence overrated? J Acquir Immune Defic Syndr. 2004;35(2):203-4

23. Nieuwkerk PT, de Boer-van der Kolk IM, Prins JM, Locadia M, Sprangers MA. Self-reported adherence is more predictive of virological treatment response among patients with a lower tendency towards socially desirable responding. Antivir Ther. 2010;15(6):913-6.

24. Alcaide ML, Ramlagan S, Rodriguez VJ, Cook R, Peltzer K, Weiss SM, et al. Self-report and dry blood spot measurement of antiretroviral medications as markers of adherence in pregnant women in rural South Africa. AIDS Behav. 2017:21(7):2135-40.

25. Berg KM, Wilson IB, Li X, Arnsten JH. Comparison of antiretroviral adherence questions. AIDS Behav. 2012;16(2):461-8.

26. Blumenthal J, Pasipanodya EC, Jain S, Sun S, Ellorin E, Morris S, et al. Comparing self-report pre-exposure prophylaxis adherence questions to pharmacologic measures of recent and cumulative pre-exposure prophylaxis exposure. Front Pharmacol. 2019;10:721.

27. Zhou G, Li X, Qiao S, Shen Z, Zhou Y. Influence of side effects on art adherence among PLWH in China: the moderator role of ART-related knowledge. AIDS Behav. 2018:22(3):961-70.

28. Qiao S, Li X, Zhou Y, Shen Z, Tang Z, Stanton B. The role of enacted stigma in parental HIV disclosure among HIV-infected parents in China. AIDS Care. 2015;27(Suppl 1):28-35.

29. Atanga PN, Ndetan HT, Fon PN, Meriki HD, Muffih TP, Achidi EA, et al. Using a composite adherence tool to assess ART response and risk factors of poor adherence in pregnant and breastfeeding HIV-positive Cameroonian women at 6 and 12 months after initiating option B. BMC Pregnancy Childbirth. 2018;18(1):418.

30. Gandhi M, Greenblatt RM. Hair it is: the long and short of monitoring antiretroviral treatment. Ann Intern Med. 2002;137(8):696-7.

31. Zhang Q, Qiao S, Yang X, Li X. Antiretroviral concentration in hair as a measure for antiretroviral medication adherence: a systematic review of global literature. AIDS Behav. 2020;24(1):311-30.

32. Seifert SM, Castillo-Mancilla JR, Erlandson K, Morrow M, Gandhi M, Kuncze $\mathrm{K}$, et al. Brief report: adherence biomarker measurements in older and younger HIV-infected adults receiving tenofovir-based therapy. J Acquir Immune Defic Syndr. 2018;77(3):295-8.

33. Gandhi M, Murnane PM, Bacchetti P, Elion R, Kolber MA, Cohen SE, et al. Hair levels of preexposure prophylaxis drugs measure adherence 
and are associated with renal decline among men/transwomen. AIDS 2017;31(16):2245-51.

34. Gandhi M, Glidden DV, Liu A, Anderson PL, Horng H, Defechereux P, et al. Strong correlation between concentrations of tenofovir (TFV) emtricitabine (FTC) in hair and TFV diphosphate and FTC triphosphate in dried blood spots in the iPrEx open label extension: implications for pre-exposure prophylaxis adherence monitoring. J Infect Dis. 2015;212(9):1402-6.

35. Abaasa A, Hendrix C, Gandhi M, Anderson P, Kamali A, Kibengo F, et al. Utility of different adherence measures for PrEP: patterns and incremental value. AIDS Behav. 2018;22(4):1165-73.

36. Liu AY, Yang Q, Huang Y, Bacchetti P, Anderson PL, Jin C, et al. Strong relationship between oral dose and tenofovir hair levels in a randomized trial: hair as a potential adherence measure for pre-exposure prophylaxis (PrEP). PLoS ONE. 2014;9(1):e83736.

37. Yang X, Li X, Qiao S, Zhang Q, Shen Z, Zhou Y. Immunological and virologic outcomes of people living with HIV in Guangxi, China: 2012-2017. PLOS ONE. 2019;14(3):e0213205.

38. Cooper GA, Kronstrand R, Kintz P, Society of Hair T. Society of Hair Testing guidelines for drug testing in hair. Forensic Sci Int. 2012;218(1-3):20-4.

39. Sachs H. Quality control by the Society of Hair Testing. Forensic Sci Int. 1997:84(1-3):145-50.

40. Wu Y, Yang J, Duan C, Chu L, Chen S, Qiao S, Li X, Deng H. Simultaneous determination of antiretroviral drugs in human hair with liquid chromatography-electrospray ionization-tandem mass spectrometry. J Chromatogr B Analyt Technol Biomed Life Sci. 2018;1083:209-21.

41. Chu L, Wu Y, Duan C, Yang J, Yang H, Xie Y, Zhang Q, Qiao S, Li X, Shen Z, Deng $\mathrm{H}$. Simultaneous quantitation of zidovudine, efavirenz, lopinavir and ritonavir in human hair by liquid chromatography-atmospheric pressure chemical ionization-tandem mass spectrometry. J Chromatogr B Analyt Technol Biomed Life Sci. 2018;1097-1098:54-63.

42. Baxi SM, Vittinghoff E, Bacchetti P, Huang Y, Chillag K, Wiegand R, et al. Comparing pharmacologic measures of tenofovir exposure in a U.S. preexposure prophylaxis randomized trial. PLoS ONE. 2018;13(1):e0190118.

43. Koss CA, Bacchetti P, Hillier SL, Livant E, Horng H, Mgodi N, et al. Differences in cumulative exposure and adherence to tenofovir in the VOICE,
iPrEx OLE, and PrEP Demo studies as determined via hair concentrations. Aids Res Hum Retrovir. 2017;33(8):778-83.

44. Bartelink IH, Savic RM, Mwesigwa J, Achan J, Clark T, Plenty A, et al. Pharmacokinetics of lopinavir/ritonavir and efavirenz in food insecure HIV-infected pregnant and breastfeeding women in Tororo, Uganda. J Clin Pharmacol. 2014;54(2):121-32.

45. Chawana TD, Gandhi M, Nathoo K, Ngara B, Louie A, Horng H, et al. Defining a cutoff for atazanavir in hair samples associated with virological failure among adolescents failing second-line antiretroviral treatment. J Acquir Immune Defic Syndr. 2017;76(1):55-9.

46. Gandhi M, Greenblatt RM, Bacchetti P, Jin C, Huang Y, Anastos K, et al. A single-nucleotide polymorphism in CYP2B6 leads to $>3$-fold increases in efavirenz concentrations in plasma and hair among HIV-infected women. J Infect Dis. 2012;206(9):1453-61.

47. Olds PK, Kiwanuka JP, Nansera D, Huang Y, Bacchetti P, Jin C, et al. Assessment of HIV antiretroviral therapy adherence by measuring drug concentrations in hair among children in rural Uganda. AIDS Care. 2015;27(3):327-32.

48. Haberer JE. Current concepts for PrEP adherence in the PrEP revolution: from clinical trials to routine practice. Curr Opin HIV AIDS. 2016;11(1):10-7.

49. Stalter RM, Moench TR, MacQueen KM, Tolley EE, Owen DH, Consortium for Ring A. Biomarkers and biometric measures of adherence to use of ARV-based vaginal rings. J Int AIDS Soc. 2016;19(1):20746.

50. Chesney MA. Factors affecting adherence to antiretroviral therapy. Clin Infect Dis. 2000;30(Suppl 2):S171-6.

51. Zhang Q, Li X, Qiao S, Yang X. Factors related to hair antiretroviral concentration: a systematic review of global literature. AIDS Rev. 2019. https:// doi.org/10.24875/AIDSRev.19000122.

\section{Publisher's Note}

Springer Nature remains neutral with regard to jurisdictional claims in published maps and institutional affiliations.
Ready to submit your research? Choose BMC and benefit from:

- fast, convenient online submission

- thorough peer review by experienced researchers in your field

- rapid publication on acceptance

- support for research data, including large and complex data types

- gold Open Access which fosters wider collaboration and increased citations

- maximum visibility for your research: over $100 \mathrm{M}$ website views per year

At $\mathrm{BMC}$, research is always in progress.

Learn more biomedcentral.com/submissions 